\title{
Acute kidney injury after nephrectomy: a new nomogram to predict postoperative renal function
}

Lingyu Xư ${ }^{\dagger}$, Chenyu Li ${ }^{\dagger}$, Long Zhao, Bin Zhou, Congjuan Luo, Xiaofei Man, Hong Luan, Lin Che, Yanfei Wang and $\operatorname{Yan} X u^{*}(1)$

\begin{abstract}
Background: We aimed to develop a nomogram based on preprocedural features for early prediction of acute kidney injury (AKI) and to assess the prognosis in patients after radical and partial nephrectomy.

Methods: The study included a development cohort of 1111 patients who were treated between June 2012 and June 2017 and an additional validation cohort of 356 patients who were treated between July 2017 and June 2018. Stepwise regression and logistic regression analyses were used to evaluate the association between predictors and AKI. Incorporating all independent predictors, a nomogram for postoperative AKI was developed and externally validated. Patients were followed up for 5 years to assess renal function, acute kidney disease (AKD), chronic kidney disease (CKD), hospital readmission and mortality were key prognosis we focused on.

Results: After multivariate logistic regression, radical nephrectomy (odds ratio $(\mathrm{OR})=3.57, p<0.001)$, aspirin $(\mathrm{OR}=1.79$, $p=0.008)$, systolic blood pressure $(\mathrm{OR}=1.41, p=0.004)$, triglyceride $(\mathrm{OR}=1.26, p=0.024)$, and alkaline phosphatase $(\mathrm{OR}=1.75, p=0.034)$ were independent risk factors for postoperative $\mathrm{AKl}$, while albumin $(\mathrm{OR}=0.72, p=0.031)$ was a protective factor for postoperative AKI. Patients with a higher estimated glomerular filtration rate (eGFR) $(60-90 \mathrm{ml} / \mathrm{min} /$ $1.73 \mathrm{~m}^{2}, \mathrm{OR}=0.41, p=0.004 ; \geq 90 \mathrm{ml} / \mathrm{min} / 1.73 \mathrm{~m}^{2}, \mathrm{OR}=0.37, p<0.001$ ) were less prone to AKI than those with a lower eGFR $\left(<15 \mathrm{ml} / \mathrm{min} / 1.73 \mathrm{~m}^{2}\right)$. These predictors were all included in the final nomogram. The area under the receiver operating characteristics curve for the model were $0.77(p<0.001)$ in the development cohort and $0.72(p<0.001)$ in the validation cohort. The incidence of AKD and CKD were 27.12 and $18.64 \%$ in AKI group, which were much higher than those in no AKI group $(p<0.001)$.
\end{abstract}

Conclusions: The nomogram had excellent predictive ability and might have significant clinical implications for the early detection of AKI in patients undergoing nephrectomy.

Keywords: Nephrectomy, Renal function, Acute kidney injury, Predictor, Nomogram, Prognosis

\footnotetext{
*Correspondence: xuyanayfy@126.com

${ }^{\dagger}$ Lingyu Xu and Chenyu Li contributed equally to this work.

Department of Nephrology, The Affiliated Hospital of Qingdao University, 16

Jiangsu Road, Qingdao 266003, China
}

(c) The Author(s). 2020 Open Access This article is licensed under a Creative Commons Attribution 4.0 International License, which permits use, sharing, adaptation, distribution and reproduction in any medium or format, as long as you give appropriate credit to the original author(s) and the source, provide a link to the Creative Commons licence, and indicate if changes were made. The images or other third party material in this article are included in the article's Creative Commons licence, unless indicated otherwise in a credit line to the material. If material is not included in the article's Creative Commons licence and your intended use is not permitted by statutory regulation or exceeds the permitted use, you will need to obtain permission directly from the copyright holder. To view a copy of this licence, visit http://creativecommons.org/licenses/by/4.0/ The Creative Commons Public Domain Dedication waiver (http://creativecommons.org/publicdomain/zero/1.0/) applies to the data made available in this article, unless otherwise stated in a credit line to the data. 


\section{Background}

Renal masses are a biologically heterogeneous group of tumors ranging from benign masses to cancers that are commonly encountered in urologic practice; renal cell carcinoma (RCC) is the most lethal urological malignancy, and angiomyolipoma is the most common benign entity [1-3]. The standard treatment is surgical excision, including radical nephrectomy $(\mathrm{RN})$ or partial nephrectomy (PN) and laparotomy or minimally invasive approaches [4,5]. RN has been the standard surgical therapy for localized renal masses for many decades [6$8]$, even though this treatment may lead to a rapid decline in renal function and an increased risk of chronic kidney disease (CKD), which causes death in the short or long term [9-14]. In contrast, $\mathrm{PN}$ is more effective for preserving renal function [15-17]. In recent years, abdominal computed tomography and magnetic resonance imaging have made detection of smaller renal masses possible, which assists urologists in conducting early clinical interventions before tumor progression and metastasis. Therefore, compared to RN, which involves removal of the whole kidney, $\mathrm{PN}$ is emphasized in the management of patients with clinical T1 renal masses that can be cured $[10,13]$, while $R N$ remains the standard surgery for tumors $>7 \mathrm{~cm}$ (T2 or more) $[4,17,18]$. In addition to $\mathrm{PN}$ and $\mathrm{RN}$, there has also been an evolution in surgical management, and minimally invasive nephrectomy has gained importance as an alternative treatment to laparotomy.

Although surgery may become the preferred choice for urologists, studies have reported that nephrectomy is associated with a high iatrogenic risk of acute kidney injury (AKI) [11, 19-21]. AKI, a serious medical condition and complication characterized by persistent oliguria and elevated serum creatinine (Scr) level, is associated with high morbidity and mortality, especially after surgery and in the intensive care unit (ICU) [22, 23]. The pathophysiology of postoperative AKI involves various factors, and previous studies have developed several mathematical models to assess the risk of AKI. These proposed models were postprocedural and contained some intraoperative factors, such as anesthesiologists' score and operative duration. Patients must undergo surgery to have this information obtained [21, 24-26], which is untimely to conduct clinical intervention. From our perspective, there is no conclusion regarding which factor can lead to AKI after nephrectomy, and identifying risk factors may aid in the application of preoperative preventative methods for patients. Therefore, a risk model with quick applicability to assess AKI risk prior to the procedure may be timely and clinically important. This is a pioneering study to assess various predictors and to develop a model for the prediction of postoperative AKI before nephrectomy. And patients were followed up for 5 years to analyze the incidence of acute kidney disease (AKD), CKD, hospital readmission and death.

A nomogram is a visual tool that has been increasingly utilized to visualize an approximate graphical calculation of regression models, which can assist clinicians in predicting patient outcomes and making clinical decisions. Based on logistic regression, we innovatively used a nomogram to explore the relationship between predictors and postoperative AKI. By integrating these clinical factors, a nomogram can provide individualized estimates of the probability of an outcome. Therefore, these algorithms might be used as reliable tools for predicting AKI and guiding decisions regarding nephrectomy.

\section{Methods}

Study population and data collection

Our hospital is one of the top 100 hospitals in China. Its subordinate urology department, the provincial key discipline, has 7 high level physicians with more than 10 years of surgical experience, and more than 400 cases of nephrectomy are performed each year. The development cohort included patients who underwent nephrectomy between June 2012 and June 2017, while the validation cohort was collected between July 2017 and June 2018. We further study 5-year prognosis of patients after nephrectomy, AKD, CKD, hospital readmission and mortality were key outcomes we focused on. Patients were excluded if they met one of the following characteristics:

(1) Patients with radical nephroureterectomy or renal cystic unroofing.

(2) Patients with a duplex kidney or solitary kidney.

(3) Patients requiring dialysis before nephrectomy.

(4) Patients with donor nephrectomies.

(5) Patients with missing data elements needed further analysis.

\section{Covariates}

First, we assessed the demographic information of all patients: age at surgery, gender, body mass index (BMI), smoking and alcohol status. Additionally, preoperative data, such as routine blood tests, coagulation markers, blood biochemical examinations, urinalyses, and blood pressure measurements were collected simultaneously. Operative information included the procedure type ( $\mathrm{RN}$ and $\mathrm{PN}$ ), approach (laparoscopic, open, or robotic) for nephrectomy. Comorbidities and the usage of drugs, such as angiotensin-converting enzyme inhibitors/angiotensin receptor blockers (ACEIs/ARBs), calcium channel blocker (CCB), $\beta$-adrenergic antagonists, nonsteroidal anti-inflammatory drugs (NSAIDs), aspirin, 
Table 1 Characteristics of 1111 patients at risk of AKI after nephrectomy in development cohort

\begin{tabular}{|c|c|c|c|c|c|}
\hline Variables & Total no. (\%) & No AKI no. (\%) & AKI no. (\%) & $t / x^{2}$ & $P$-value \\
\hline No.of patients & $1111(100)$ & 875 (78.76) & $236(21.24)$ & - & - \\
\hline Age, y, mean (SD) & $55.17(12.59)$ & $54.56(12.49)$ & $57.47(12.70)$ & 3.17 & 0.002 \\
\hline \multicolumn{6}{|l|}{ Gender } \\
\hline Female & $472(42.48)$ & $398(45.49)$ & $74(31.36)$ & \multirow[t]{2}{*}{15.19} & \multirow[t]{2}{*}{$<0.001$} \\
\hline Male & $639(57.52)$ & $477(54.51)$ & $162(68.64)$ & & \\
\hline $\mathrm{BMI}, \mathrm{kg} / \mathrm{m}^{2}$, mean (SD) & $25.12(3.33)$ & $25.00(3.33)$ & $25.56(3.28)$ & 2.28 & 0.023 \\
\hline \multicolumn{6}{|l|}{ Procedure } \\
\hline Partial nephrectomy & $360(32.40)$ & 314 (35.89) & $46(19.49)$ & \multirow[t]{2}{*}{22.81} & \multirow[t]{2}{*}{$<0.001$} \\
\hline Radical nephrectomy & $751(67.60)$ & $561(64.11)$ & $190(80.51)$ & & \\
\hline \multicolumn{6}{|l|}{ Approach } \\
\hline Laparoscopic & $821(73.90)$ & 647 (73.94) & $174(73.73)$ & \multirow[t]{3}{*}{0.26} & \multirow[t]{3}{*}{0.877} \\
\hline Open & $204(18.36)$ & $162(18.51)$ & $42(17.80)$ & & \\
\hline Robotic & $86(7.74)$ & $66(7.54)$ & $20(8.47)$ & & \\
\hline \multicolumn{6}{|l|}{ Baseline laboratory values } \\
\hline Mean PLT, × 109/L (SD) & $245.45(76.70)$ & $246.48(76.89)$ & $241.60(76.07)$ & 0.87 & 0.390 \\
\hline Mean FIB, g/L (SD) & $3.18(1.04)$ & $3.18(1.07)$ & $3.21(0.96)$ & 0.37 & 0.712 \\
\hline Mean PCT, ng/ml (SD) & $0.24(0.07)$ & $0.24(0.07)$ & $0.24(0.07)$ & 0.55 & 0.582 \\
\hline Mean MPV, fl (SD) & $9.83(1.05)$ & $9.81(1.06)$ & $9.88(1.00)$ & 0.84 & 0.402 \\
\hline Mean Hb, g/L (SD) & $135.90(19.70)$ & $135.92(19.28)$ & $135.80(21.22)$ & 0.08 & 0.930 \\
\hline Mean MCHC, g/L (SD) & $333.72(12.62)$ & $333.88(12.60)$ & $333.15(12.71)$ & 0.78 & 0.434 \\
\hline Mean MCH, pg (SD) & $29.82(2.36)$ & $29.84(2.32)$ & $30.05(2.50)$ & 1.34 & 0.181 \\
\hline Mean MCV, fL (SD) & $89.42(5.57)$ & $89.23(5.44)$ & $90.11(6.02)$ & 2.15 & 0.032 \\
\hline Mean ALT, U/L (SD) & $21.33(15.91)$ & $21.30(16.23)$ & $21.46(14.67)$ & 0.14 & 0.886 \\
\hline Mean AST, U/L (SD) & $18.32(8.78)$ & $18.41(9.35)$ & $17.80(6.23)$ & 0.64 & 0.520 \\
\hline Mean STB, $\mu \mathrm{mol} / \mathrm{L}$ (SD) & $14.98(6.57)$ & $14.94(6.57)$ & $15.10(6.58)$ & 0.33 & 0.740 \\
\hline Mean CHOL, mmol/L (SD) & $5.02(1.10)$ & $5.06(1.11)$ & $4.88(1.05)$ & 2.20 & 0.028 \\
\hline Mean TG, mmol/L (SD) & $1.41(1.09)$ & $1.38(1.07)$ & $1.51(1.16)$ & 1.60 & 0.111 \\
\hline Mean TP, g/L (SD) & $68.77(6.03)$ & $69.00(6.01)$ & $67.90(6.03)$ & 2.51 & 0.012 \\
\hline Mean ALB, g/L (SD) & $40.06(4.62)$ & $40.20(4.62)$ & $39.51(4.57)$ & 2.04 & 0.041 \\
\hline Mean ALP, U/L (SD) & $75.05(35.52)$ & $74.12(34.04)$ & $78.46(40.44)$ & 1.67 & 0.096 \\
\hline Mean LDH, U/L (SD) & $164.75(60.47)$ & 163.69 (63.09) & $168.67(49.47)$ & 1.29 & 0.198 \\
\hline Mean HDL, mmol/L (SD) & $1.36(0.34)$ & $1.38(0.34)$ & $1.30(0.32)$ & 3.36 & 0.001 \\
\hline Mean TT\%, \% (SD) & $1.07(0.10)$ & $1.07(0.10)$ & $1.07(0.09)$ & 0.46 & 0.646 \\
\hline Mean TT, s (SD) & $14.66(2.05)$ & $14.75(2.12)$ & $14.36(1.74)$ & 2.60 & 0.009 \\
\hline Mean GLU, mmol/L (SD) & $5.58(1.87)$ & $5.59(1.95)$ & $5.55(1.53)$ & 0.24 & 0.811 \\
\hline Mean HCT, \% (SD) & $40.48(5.55)$ & $40.49(5.43)$ & $40.45(5.97)$ & 0.10 & 0.921 \\
\hline Mean UA, $\mu \mathrm{mol} / \mathrm{L}$ (SD) & $320.69(90.15)$ & $317.21(89.77)$ & $333.60(90.60)$ & 2.47 & 0.014 \\
\hline Mean SBP, mmHg (SD) & $130.30(17.37)$ & $129.64(17.17)$ & $132.76(17.93)$ & 2.45 & 0.014 \\
\hline Mean DBP, mmHg (SD) & $81.11(10.97)$ & $80.93(10.73)$ & $81.80(11.84)$ & 1.09 & 0.276 \\
\hline \multicolumn{6}{|c|}{ Preoperative eGFR, $\mathrm{ml} / \mathrm{min} / 1.73 \mathrm{~m}^{2}$} \\
\hline$<60$ & $127(11.43)$ & $96(10.97)$ & $31(13.14)$ & 36.41 & $<0.001$ \\
\hline$\geq 60$ & $984(88.57)$ & 779 (89.03) & $205(86.86)$ & & \\
\hline \multicolumn{6}{|l|}{ Comorbidities } \\
\hline Hypertension & 333 (29.97) & $242(27.66)$ & 91 (38.56) & 10.53 & 0.001 \\
\hline
\end{tabular}


Table 1 Characteristics of 1111 patients at risk of AKI after nephrectomy in development cohort (Continued)

\begin{tabular}{|c|c|c|c|c|c|}
\hline Variables & Total no. (\%) & No AKI no. (\%) & AKI no. (\%) & $t / x^{2}$ & $P$-value \\
\hline Diabetes mellitus & $131(11.79)$ & $100(11.43)$ & $31(13.14)$ & 0.52 & 0.471 \\
\hline $\mathrm{CHD}$ & $85(7.65)$ & $63(7.20)$ & $22(9.32)$ & 1.19 & 0.276 \\
\hline PU & $46(4.14)$ & $35(4.00)$ & $11(4.66)$ & 0.21 & 0.651 \\
\hline FLD & $53(4.77)$ & $39(4.46)$ & $14(5.93)$ & 0.89 & 0.345 \\
\hline CKD & $5(0.45)$ & $0(0.00)$ & $5(2.12)$ & 18.62 & $<0.001$ \\
\hline Cystic kidney disease & $135(12.15)$ & $105(12.00)$ & $30(12.71)$ & 0.09 & 0.766 \\
\hline Renal calculi & $126(11.34)$ & $119(13.60)$ & $7(2.97)$ & 20.90 & $<0.001$ \\
\hline Hydronephrosis & $107(9.63)$ & $101(11.54)$ & $6(2.54)$ & 17.30 & $<0.001$ \\
\hline \multicolumn{6}{|l|}{ Drugs } \\
\hline ACEIs/ARBs & $123(11.07)$ & $92(10.51)$ & $31(13.14)$ & 1.30 & 0.255 \\
\hline $\mathrm{CCB}$ & $249(22.41)$ & $178(20.34)$ & $71(30.08)$ & 10.14 & 0.001 \\
\hline$\beta$-adrenergic antagonists & $469(42.21)$ & $371(42.40)$ & $98(41.53)$ & 0.06 & 0.809 \\
\hline NSAIDs & $263(23.67)$ & $208(23.77)$ & $55(23.31)$ & 0.02 & 0.881 \\
\hline Aspirin & $174(15.66)$ & $129(14.74)$ & $45(19.07)$ & 2.63 & 0.105 \\
\hline Aminoglycoside antibiotics & $53(4.77)$ & $11(4.66)$ & $42(4.80)$ & 0.01 & 0.929 \\
\hline Quinolones & $158(14.22)$ & $131(14.97)$ & $27(11.44)$ & 1.90 & 0.168 \\
\hline$\beta$-Lactams & $258(23.22)$ & $199(22.74)$ & $59(25.00)$ & 0.53 & 0.466 \\
\hline PPI & $1086(97.75)$ & $856(97.83)$ & $230(97.46)$ & 0.12 & 0.733 \\
\hline Metformin & $35(3.15)$ & $26(2.97)$ & $9(3.81)$ & 0.43 & 0.511 \\
\hline \multicolumn{6}{|l|}{ Life style } \\
\hline Alcohol & $321(28.89)$ & $233(26.63)$ & $88(37.29)$ & 10.28 & 0.001 \\
\hline Smoking & 375 (33.75) & $286(32.69)$ & $89(37.71)$ & 2.10 & 0.147 \\
\hline \multicolumn{6}{|l|}{ Insurance status } \\
\hline Yes & 979 (88.12) & $772(88.23)$ & $207(87.71)$ & 0.05 & 0.828 \\
\hline No & $132(11.88)$ & $103(11.77)$ & $29(12.29)$ & & \\
\hline Length of hospital stay & $10.99(3.80)$ & $11.07(3.60)$ & $10.69(4.45)$ & 2.86 & 0.004 \\
\hline \multicolumn{6}{|l|}{ Prognosis } \\
\hline AKD & $127(11.43)$ & $63(7.20)$ & $64(27.12)$ & 72.84 & $<0.001$ \\
\hline CKD & $96(8.64)$ & $52(5.94)$ & $44(18.64)$ & 37.98 & $<0.001$ \\
\hline Hospital readmission & $142(12.78)$ & $74(8.46)$ & $68(28.81)$ & 69.09 & $<0.001$ \\
\hline
\end{tabular}

Note: numbers in bold mean they are significance $(p<0.05)$

Abbreviations: AKI Acute kidney injury, SD Standard deviation, BMI Body mass index, PLT Platelet, FIB Fibrinogen, PCT Platelet crit, MPV Mean platelet volume, Hb Hemoglobin, MCHC Mean corpuscular hemoglobin concentration, MCH Mean corpuscular hemoglobin, MCV Mean corpuscular volume, ALT Alanine transaminase, AST Aspartate transaminase, STB Total bilirubin, CHOL Cholesterol, TG Triglyceride, TP Total protein, ALB Albumin, ALP Alkaline phosphatase, LDH Lactate dehydrogenase, HDL High density lipoprotein, $T T$ Thrombin time, GLU Glucose, HCT Hematocrit, UA Uric acid, SBP Systolic blood pressure, DBP Diastolic blood pressure, eGFR Estimated glomerular filtration rate, CHD Coronary heart disease, $P U$ Peptic ulcer, FLD Fatty liver disease, CKD Chronic kidney disease, $A C E / s$ Angiotensin-converting enzyme inhibitors, ARBs Angiotensin receptor blockers, CCB Calcium channel blocker, NSAIDs Non-steroidal anti-inflammatory drugs, PPI Proton pump inhibitor, $A K D$ Acute kidney disease

aminoglycoside antibiotics, quinolones, $\beta$-lactams, proton pump inhibitor (PPI), and metformin were also collected. Moreover, prognosis (AKD, CKD, hospital readmission and mortality) were followed up as well. The estimated glomerular filtration rate (eGFR) was calculated using the Chronic Kidney Disease Epidemiology Collaboration (CKD-EPI) creatinine formula, a 4-variable equation consisting of age, race, gender, and Scr level [27, 28]. Other details are listed in Table 1.

\section{Outcome definition}

The primary endpoint was postoperative AKI, which identified based on latest Kidney Disease: Improving Global Outcomes (KDIGO) Clinical Practice Guideline [29] for AKI: (1) Increase in Scr level by $\geq 26.5 \mu \mathrm{mol} / \mathrm{L}$ $(0.3 \mathrm{mg} / \mathrm{dL})$ within $48 \mathrm{~h}$; (2) Increase in Scr level to $\geq 1.5$ times baseline, which is known or presumed to have occurred within the prior 7 days (Additional file 1). The most recent Scr level before nephrectomy was selected as the baseline Scr. The second endpoint was AKD, 
CKD, hospital readmission and mortality. AKD was defined as a condition in which AKI stage 1 or greater was present $\geq 7$ days after an AKI initiating event [30], while AKD that persisted beyond 90 days was considered to be CKD [31].

\section{Statistical analysis}

Numerical variables are expressed as the mean \pm standard deviation (SD), while descriptive statistics of categorical variables are reported as frequencies and proportions. Continuous and categorical variables were compared by Student's t-test and the $x^{2}$-test or Fisher's exact test, respectively. For further analyses, continuous variables were transformed into categorical variables. Then, we performed stepwise and logistic regression analyses with postoperative AKI as the dependent variable, and the results are presented as odds ratios (ORs) and 95\% confidence intervals (CIs). Incorporating all independent predictors, a logistic regression-based nomogram to predict the risk of postoperative AKI was developed and externally validated using the validation cohort. Survival analysis was used to assess prognosis and multiple imputation was used to estimate missing data. All statistical analyses were performed using the Statistical Package SPSS (version 23.0, SPSS Inc., Chicago, IL, USA) and R software (The R Foundation for Statistical Computing, www.R-project.org), with a 2-sided significance level set at $p<0.05$.

\section{Results}

\section{Baseline characteristics}

Initially, the development cohort included 1900 patients who underwent nephrectomy between June 2012 and June 2017, and the additional validation cohort consisted of
513 patients who were treated between July 2017 and June 2018. After screening based on the exclusion criteria, the remaining 1111 (58.47\%) and 356 (69.40\%) patients were included in the final analyses (Fig. 1). From 2013 to 2016, 941 patients underwent nephrectomy. Among them, RN $(68.23 \%)$ was more than two times as frequently as PN (31.77\%), and laparoscopic RN was the predominant treatment approach. Because of the introduction of robotic surgical systems, the use of robotic PN (0 to 8.15\%) increased year by year, whereas the rates of open PN (1.75 to $1.69 \%$ ) and laparoscopic $\mathrm{PN}$ (26.32 to $26.12 \%$ ) remained relatively unchanged. (Additional file 2).

Patients underwent RN were more susceptible to postoperative AKI than PN patients $(p<0.001)$. According to baseline laboratory values, RN patients had higher platelet (PLT) counts, fibrinogen (FIB), alkaline phosphatase (ALP), and lactate dehydrogenase (LDH) levels $(p<$ 0.01 ), while patients who underwent PN had higher hemoglobin $(\mathrm{Hb})$, mean corpuscular hemoglobin concentration (MCHC), mean corpuscular hemoglobin $(\mathrm{MCH})$, cholesterol $(\mathrm{CHOL})$, triglyceride (TG), albumin (ALB), and hematocrit (HCT) levels $(p<0.05)$, indicating that RN patients might have worse preoperative physical conditions than patients who underwent PN. Moreover, patients with a preoperative eGFR $<60 \mathrm{ml} / \mathrm{min} / 1.73 \mathrm{~m}^{2}$ were more commonly represented in the $\mathrm{RN}$ group than in the PN group $(13.98 \%$ vs. $6.11 \%, p<0.001)$, showing worse preoperative renal function among RN patients. (Table 1 and Additional file 3).

\section{Outcome of renal function}

In the development cohort, 236 patients (21.24\%) experienced postoperative AKI. AKI patients were more likely

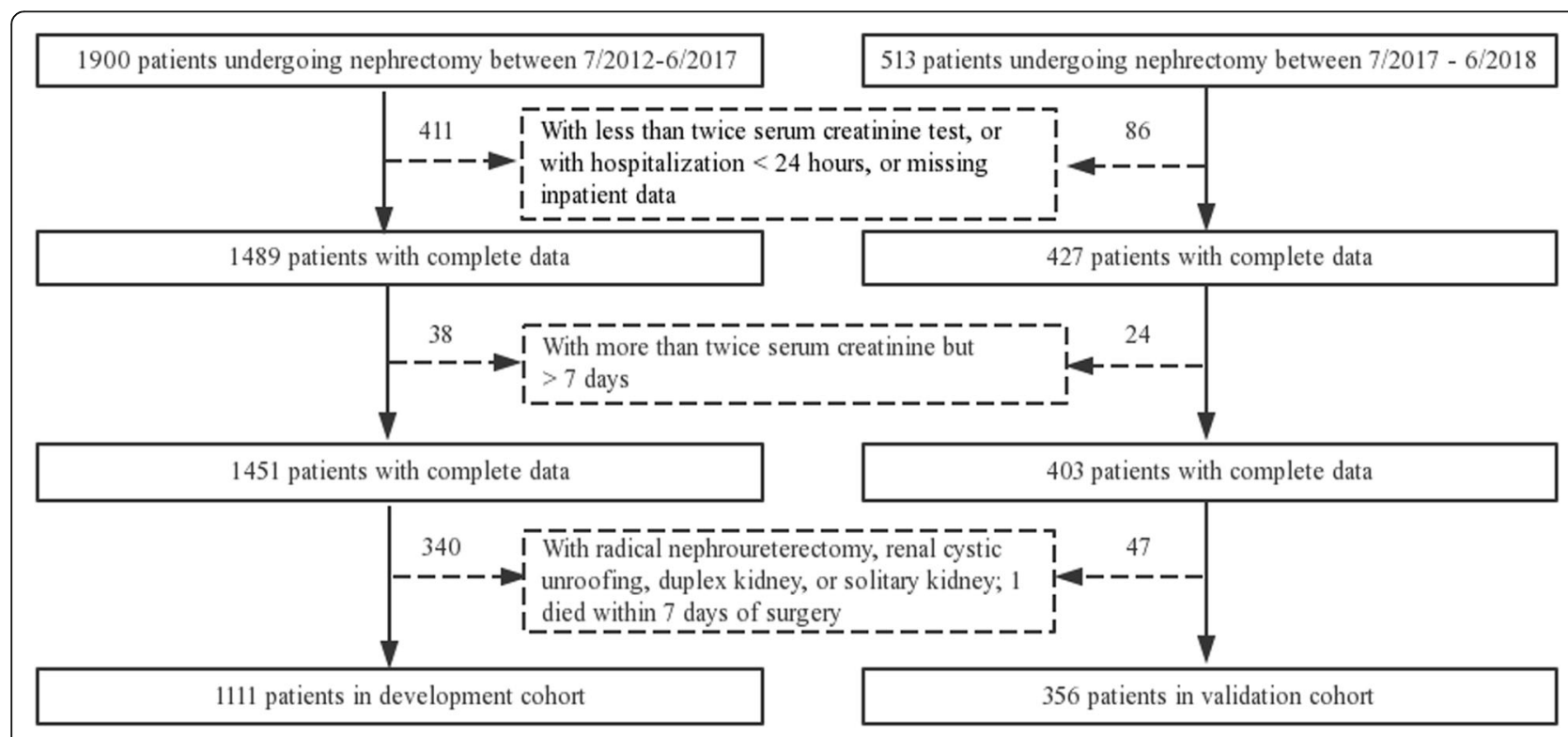

Fig. 1 Flow diagram of patients enrollment 
than patients with normal postoperative kidney function to have undergone $\mathrm{RN}$ rather than $\mathrm{PN}(80.51 \%$ vs. $64.11 \%, p<0.001$ ), but the surgical approach between the two groups was not statistically significant $(p>0.05)$. The mean preoperative thrombin time (TT), mean corpuscular volume (MCV), CHOL, total protein (TP), ALB, high density lipoprotein (HDL), uric acid (UA), and systolic blood pressure (SBP) significantly differed between the patients with and without AKI $(p<0.05)$, AKI group seemed to have a higher but relatively normal BMI level $(p=0.023)$. Compared to patients without postoperative AKI, a greater proportion of AKI patients had a preoperative eGFR $<60 \mathrm{ml} / \mathrm{min} / 1.73 \mathrm{~m}^{2}(13.14 \%$ vs. $10.97 \%, p<0.001)$. Moreover, there were 5 patients with CKD before nephrectomy who all developed AKI after surgery. All of those indicated that a relatively normal preoperative renal function might prevent patients from developing postoperative AKI. We also compared the usage of clinical drugs between different groups. Relative to patients with normal postoperative kidney function, AKI patients were more likely to use CCB (30.08\% vs. $20.34 \%, p<0.05)$, but it was excluded from the final model by stepwise regression analysis. RN patients were more likely to use aminoglycoside antibiotics, while more proportion of PN patients use aspirin $(p<$ 0.05). (Table 1 and Additional file 3).

We further study 5-year prognosis of patients after nephrectomy. There were 64 (27.12\%) AKI patients who developed AKD, while only 63 (7.20\%) in no AKI group, and the hospital readmission rate of AKI patients was also higher than without AKI (28.81\% vs. 8.46\%). Moreover, 44 AKI patients developed CKD during follow-up, which was much higher than that in no AKI group (18.64\% vs. $5.94 \%, p<0.05)$ (Fig. 2). There was only one patient who developed postoperative AKI died during follow-up. All of these results indicated that postoperative AKI might worse prognosis after nephrectomy.

\section{Multivariable analysis}

Multivariable logistic regression analysis showed that male gender $(\mathrm{OR}=1.68,95 \% \mathrm{CI}: 1.20-2.35, p=0.002)$, $\mathrm{RN} \quad(\mathrm{OR}=3.57,95 \% \mathrm{CI}: 2.42-5.26, p<0.001)$, aspirin $(\mathrm{OR}=1.79, \quad 95 \% \mathrm{CI}: 1.17-2.75, \quad p=0.008)$, high $\mathrm{PT} \%$ $(\mathrm{OR}=2.46,95 \% \mathrm{CI}: 1.15-5.24, p=0.020), \mathrm{TG}(\mathrm{OR}=1.26$, 95\%CI: $1.03-1.53, p=0.024)$, ALP $(\mathrm{OR}=1.75,95 \% \mathrm{CI}$ : $1.04-2.94, p=0.034)$, and SBP (OR $=1.41,95 \% \mathrm{CI}: 1.12-$ $1.78, p=0.004)$ were independent risk factors for postoperative AKI, while ALB (OR = 0.72, 95\%CI: 0.54-0.97,

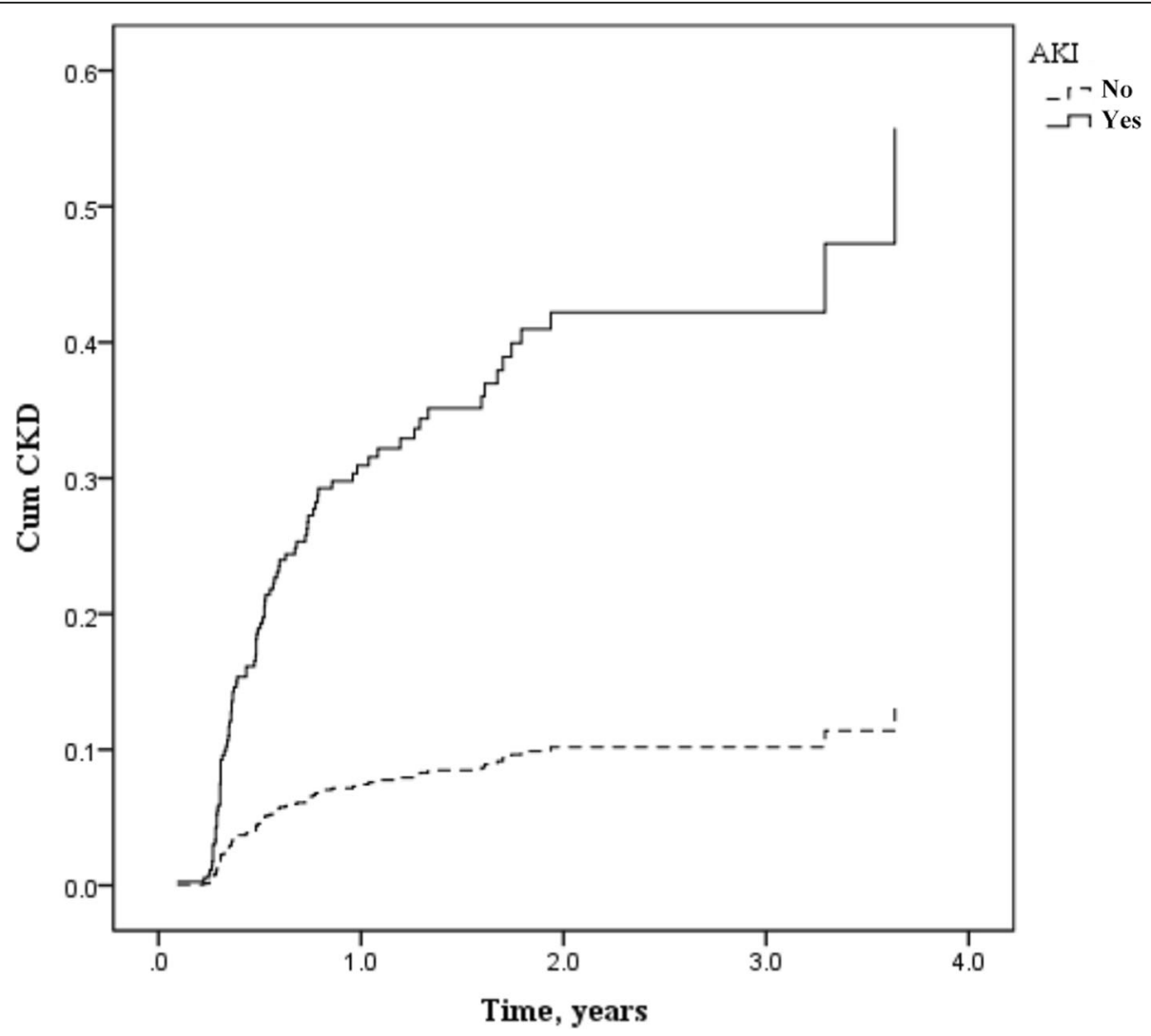

Fig. 2 CKD probabilities between AKI and no AKI patients during follow-up period 
Table 2 Multivariable logistic regression analysis for predictors of postoperative AKI

\begin{tabular}{|c|c|c|}
\hline Variables & OR $(95 \% \mathrm{Cl})$ & $p$-value \\
\hline \multicolumn{3}{|l|}{ Gender } \\
\hline Female & 1.00 & \\
\hline Male & $1.68(1.20,2.35)$ & 0.002 \\
\hline \multicolumn{3}{|l|}{ Procedure } \\
\hline Partial nephrectomy & 1.00 & \\
\hline Radical nephrectomy & $3.57(2.42,5.26)$ & $<0.001$ \\
\hline \multicolumn{3}{|l|}{ Baseline laboratory values } \\
\hline Mean TT, s & $0.65(0.47,0.89)$ & 0.007 \\
\hline Mean PCT, \% & $0.47(0.29,0.78)$ & 0.003 \\
\hline Mean PT\%, \% & $2.46(1.15,5.24)$ & 0.020 \\
\hline Mean ALB, g/L & $0.72(0.54,0.97)$ & 0.031 \\
\hline Mean TG, mmol/L & $1.26(1.03,1.53)$ & 0.024 \\
\hline Mean ALP, U/L & $1.75(1.04,2.94)$ & 0.034 \\
\hline \multicolumn{3}{|c|}{ Preoperative eGFR, $\mathrm{ml} / \mathrm{min} / 1.73 \mathrm{~m}^{2}$} \\
\hline$<15$ & 1.00 & \\
\hline $15-30$ & $2.18(0.10,47.67)$ & 0.620 \\
\hline $30-45$ & $7.14(0.80,63.58)$ & 0.078 \\
\hline $45-60$ & $1.53(0.55,4.24)$ & 0.416 \\
\hline $60-90$ & $0.41(0.22,0.76)$ & 0.004 \\
\hline$\geq 90$ & $0.37(0.26,0.53)$ & $<0.001$ \\
\hline $\mathrm{SBP}, \mathrm{mmHg}$ & $1.41(1.12,1.78)$ & 0.004 \\
\hline \multicolumn{3}{|l|}{ Comorbidities } \\
\hline Renal calculi & $0.18(0.08,0.44)$ & $<0.001$ \\
\hline Hydronephrosis & $0.23(0.09,0.56)$ & 0.001 \\
\hline \multicolumn{3}{|l|}{ Drug } \\
\hline Aspirin & $1.79(1.17,2.75)$ & 0.008 \\
\hline
\end{tabular}

Note: numbers in bold mean they are significance $(p<0.05)$

Abbreviations: AKI Acute kidney injury, OR Odds ratio, 95\% Cl 95\% confidence interval, $\pi$ thrombin time, PCT Platelet crit, $P T$ Prothrombin time, ALB Albumin, TG Triglyceride, ALP Alkaline phosphatase, eGFR Estimated glomerular filtration rate, SBP Systolic blood pressure

$p=0.031)$, TT $(\mathrm{OR}=0.65,95 \% \mathrm{CI}: 0.47-0.89, p=0.007)$, platelet crit $(\mathrm{PCT}, \mathrm{OR}=0.47,95 \% \mathrm{CI}: 0.29-0.78, p=$ 0.003 ) were protective factors for postoperative AKI. An eGFR of $60-90 \mathrm{ml} / \mathrm{min} / 1.73 \mathrm{~m}^{2} \quad(\mathrm{OR}=0.41, \quad 95 \% \mathrm{CI}$ : $0.22-0.76, p=0.004)$ or $\geq 90 \mathrm{ml} / \mathrm{min} / 1.73 \mathrm{~m}^{2}(\mathrm{OR}=0.37$, 95\%CI: $0.26-0.53, p<0.001)$ effectively prevented postoperative AKI compared with an eGFR $<15 \mathrm{ml} / \mathrm{min} /$ $1.73 \mathrm{~m}^{2}$. More details are shown in Table 2.

\section{Nomogram development}

A nomogram (Fig. 3) to predict the possibility of postoperative AKI before patients undergoing nephrectomy was developed using the results from multivariate logistic regression. Points were assigned to the thirteen identified factors according to their regression coefficients. The nomogram was internally and externally validated, and the discriminative ability was evaluated using the area under the receiver operating characteristics curve (AUC), which was 0.77 (95\% CI: 0.73-0.80, $p<0.001$ ) in the development cohort and 0.72 (95\% CI: 0.69-0.76, $p<0.001)$ in the external validation cohort. The sensitivity and specificity of the development model were 0.73 and 0.66 , and 0.86 and 0.49 in the validation cohort, indicating that the model could accurately predict postoperative AKI using preoperative predictors noted above. (Fig. 4).

\section{Discussion}

During the last 20 years, the incidence of solid renal masses has been increasing, regardless of whether the mass was benign or malignant, the main treatment was nephrectomy. However, postoperative renal dysfunction is still a constant concern faced by healthcare providers. Firstly, we focused on the short term outcome of AKI after nephrectomy by establishing a predictive model to explore which factors could promote its occurrence and development. Then, long term outcomes (AKD, CKD and hospital readmission) were also collected to assess prognosis of patients underwent nephrectomy. The incidence of postoperative AKI in our study was 21.24\%, which was relatively high compared with other studies $[17,21,32]$. And the incidence of AKD, CKD and hospital readmission in AKI patients were much higher than people without AKI after nephrectomy, indicated that postoperative AKI could accelerate the deterioration of renal function, which did worse the prognosis of nephrectomy. Compared to $\mathrm{PN}, \mathrm{RN}$ patients had a larger proportion of preoperative eGFR $<60 \mathrm{ml} / \mathrm{min} / 1.73 \mathrm{~m}^{2}$ (13.98\% vs. $6.11 \%, p<0.001$ ), and RN patients seemed to be older than PN group. After logistic regression analysis, RN was associated with a more than 3-fold increase in the odds of postoperative AKI than PN and was identified as an independent risk factor for AKI. The result was consistent with studies in which $\mathrm{RN}$ was associated with a greater risk of CKD, cardiovascular events, and even death, while better preservation of renal function after PN had been recognized to improve prognosis after nephrectomy [21, 33]. Therefore, urologists might be more inclined to choose PN for patients with smaller renal masses. The over use of RN should not be recommended for patients who have a low risk of postoperative AKI.

Many studies have been conducted to explore which factors can precisely predict postoperative AKI [21, 24], but the results are inconsistent. In this study, we created a prognostic model, including comprehensively preoperative predictors, to identify the risk of AKI after nephrectomy, which could assist urologists in taking timely clinical intervention before surgery. Among predictors identified by regression analyses, we found that a 


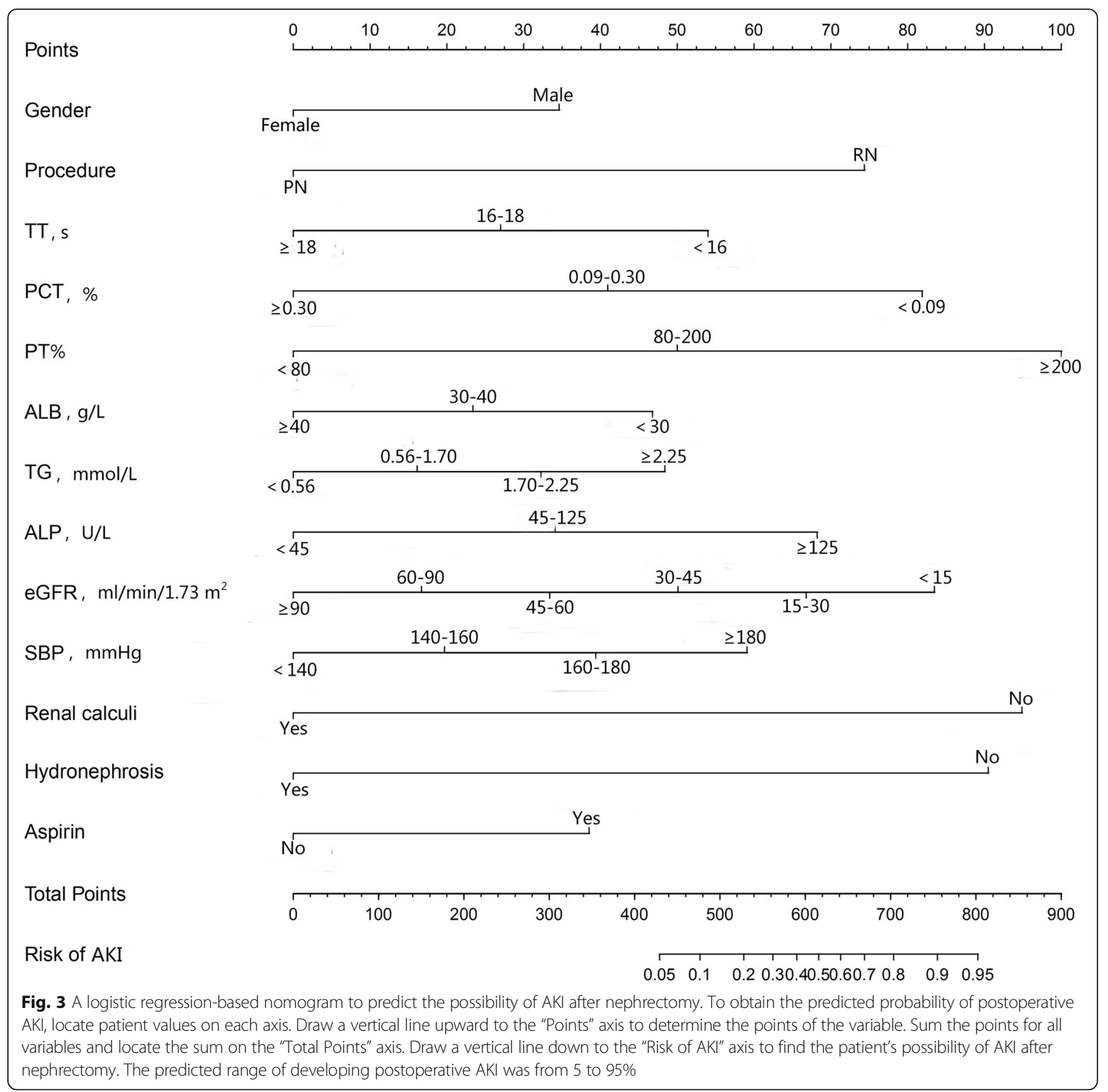

high SBP and male were risk factors for postoperative AKI, which was consistent with the findings of a previous study [34, 35], reminding urologists to control blood pressure at a safe level, especially for hypertensive patients. Another significant independent predictive factor for outcome was the preoperative eGFR. An eGFR $\geq 60$ $\mathrm{ml} / \mathrm{min} / 1.73 \mathrm{~m}^{2}$ before surgery could decrease the risk of postoperative AKI. Therefore, it is necessary for clinicians to evaluate patients' renal function before surgery. Preoperative preparation of all patients should include optimization of renal function, which might become an important measure to improve prognosis.
Renal function after nephrectomy is multifactorial and depends on presurgical factors. Therefore, our study comprehensively analyzed the relationship between preoperative laboratory values and postoperative AKI. After regression analysis, low $\mathrm{TT}, \mathrm{PCT}$, and $\mathrm{ALB}$ and high TG, PT\%, and ALP could slightly increase the risk of postoperative AKI but not as significantly as the eGFR. Hypoalbuminemia was a significant risk factor for AKI and death following AKI. The renal-protective potential of ALB includes mitigation of the nephrotoxicity of medications, protection against loss of the glycocalyx, and maintenance of glomerular filtration [36]. ALP, an 

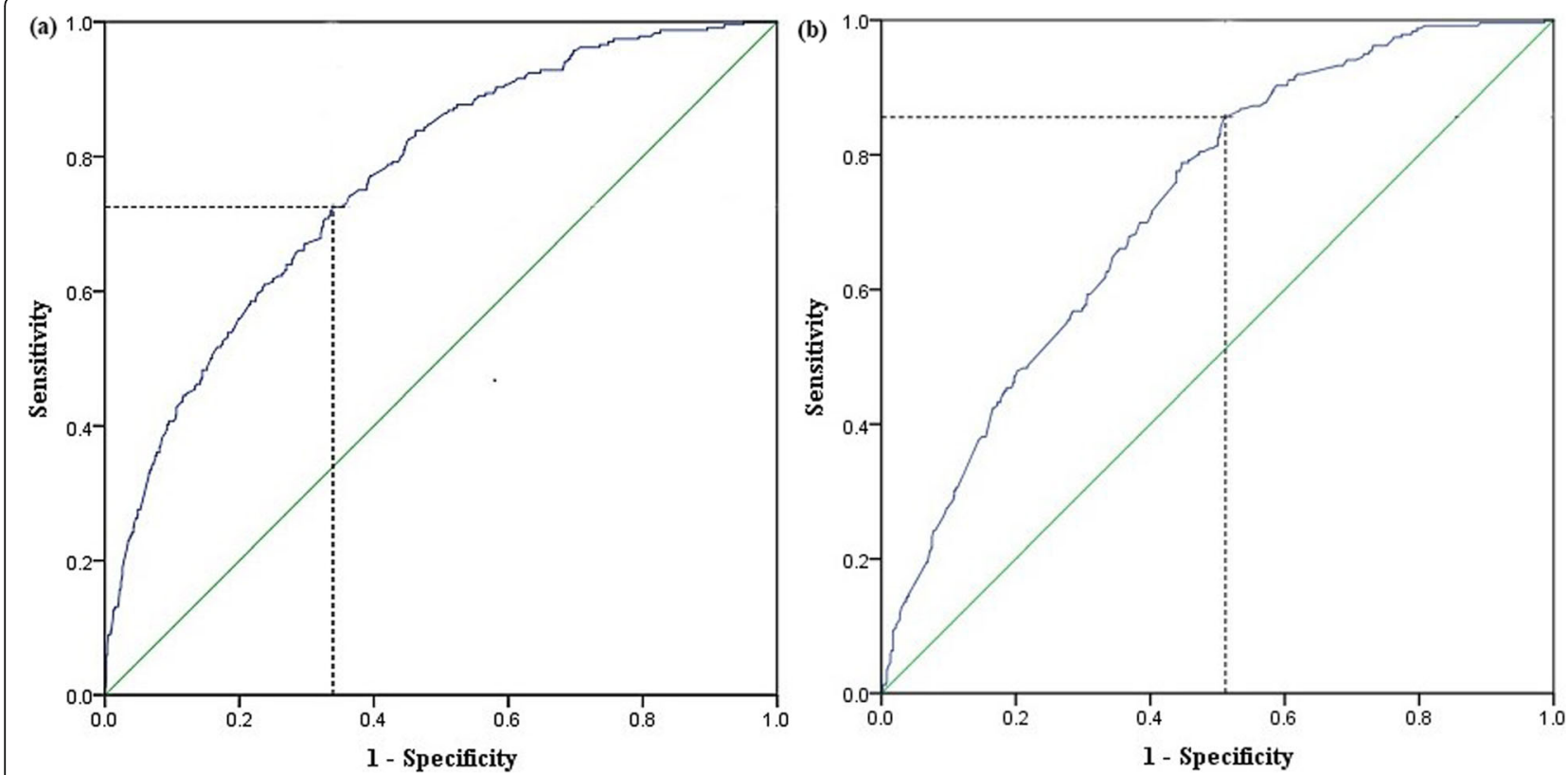

Fig. 4 Internal and external validation of the nomogram to predict the possibility of AKI after nephrectomy. The area under the receiver operating characteristic curve (AUC) were $0.77(95 \% \mathrm{Cl}: 0.73-0.80, p<0.001)$ in development cohort (a) and 0.72 (95\% Cl: $0.69-0.76, p<0.001)$ in validation cohort (b)

endogenous enzyme, exerts detoxifying effects through the dephosphorylation of endotoxins. Study showed that ALP treatment improved renal function in sepsisinduced AKI [37], indicating a protective effect after nephrectomy. Unlike data reported in a sepsis-induced AKI study, we found that the ALP level was increased in the AKI group. This finding might be due to the activation of the host defense mechanism, which promotes ALP activity at an early stage. Hypertriglyceridemia, the major type of dyslipidemia, was an independent risk factor for AKI in the early phase of acute pancreatitis [38], which can be improved by statins [39]. In our study, TG was related to postoperative AKI, which should attract attention as well.

Our study comprehensively analyzed the relationship between clinical drugs and postoperative AKI. Between the AKI and AKI free groups, there were no differences in the use of ACEIs/ARBs, $\beta$-adrenergic antagonists, PPI, NSAIDs, aminoglycoside antibiotics and other antibiotics noted above $(p>0.05)$, thus those drugs were excluded from the final model. AKI patients seemed to be more likely to use CCB (30.08\% vs. $20.34 \%, p<0.05)$, but it was excluded by stepwise regression. We further study the use of drugs in RN patients (Additional file 4), the results showed patients with preoperative eGFR $<60 \mathrm{ml} /$ $\mathrm{min} / 1.73 \mathrm{~m}^{2}$ were more likely to use ACEIs/ARBs, CCB, $\beta$-adrenergic antagonists $(p<0.05)$, but all of them were excluded by regression analysis (Additional file 5 ). It should be noted that aspirin was found harm kidney function. Aspirin, an essential medication to prevent cardiovascular disease, is known for its anti-inflammatory and antiplatelet effects. Preoperative low-dose aspirin administration was protective against AKI after cardiac surgery [40], but Sun et al reported that perioperative use of aspirin did not reduce the risk of postoperative AKI and also increased the risk of major bleeding [41]. We suggesting that there is a potential relationship between the dosage of aspirin and AKI, which requires further experiments to investigate.

Finally, based on traditional logistic regression analysis, the nomogram provides a visual method for readers to understand how the predictors impact the outcome. Moreover, synthetically analyzing all the included predictors, we could calculate the probability of the outcome exactly for every subject, which made the results more individualized. In our study, the AUC of the nomogram was $0.77(p<0.001)$ in the development cohort and $0.72(p<0.001)$ in the validation cohort, indicating that the individual probability of postoperative AKI could be predicted accurately.

The diagnosis of AKI, AKD or CKD rely on a change of Scr concentration or urine output over a defined time interval, because that preoperatively dialysis would affect Scr level [42], which could further influence the diagnosis of our outcomes, we excluded patients requiring dialysis before nephrectomy in our study. After analysis, we found that AKI patients had higher risk of developing CKD. Based on that dialysis was considered to be a main 
measure for patients with end-stage renal disease [43, 44], we guessed that postoperative AKI would increase the risk of dialysis requirement in the future.

Our study has several limitations. First, this study was conducted at a single institution, and multicenter studies should be conducted in the future. Second, because of the difficulty in data collection, we could not analyze the association between other intraoperative factors and postoperative AKI, such as anesthesiologists' score, intraoperative hydration status and urine output. However, our study aimed to develop a nomogram based on preprocedural features for early prediction of AKI, which could assist urologists in conducting early clinical interventions before nephrectomy. In addition, due to the lack of drug information, we did not further analyze the relationship between the dosage or duration of drug treatment and outcome. Therefore, more high-quality studies need to be conducted in the future. Third, in our hospital, routine urethral catheterization was conducted within 3 days after nephrectomy, the urine output was accurate during this period. After that, the urine output was recorded by family members of patients, which was not as accurate as the first 3 days. For these reasons, we did not analyze urine output, which were not as objective as blood biomarkers. Fourth, during follow-up, it is very complicated to diagnose and distinguish between AKD without previous AKI and a new AKI episode. Since the definition of initial AKI recovery is lack of consensus and real-time Scr is not easy to get from nonICU ward.

\section{Conclusion}

In conclusion, we successfully developed and validated a preoperative predictive model, a new nomogram, for AKI after nephrectomy. This predictive model will be helpful in clinical decision making regarding treatment options or follow-up strategies.

\section{Supplementary information}

Supplementary information accompanies this paper at https://doi.org/10. 1186/s12882-020-01839-0.

\section{Additional file 1. KDIGO definition and classification of AKI.}

Additional file 2 Treatment patterns of nephrectomy from 2013 to 2016. Abbreviations: LPN, laparoscopicpartial nephrectomy; OPN, open partial nephrectomy; RPN, robotic partial nephrectomy; LRN, laparoscopicradical nephrectomy; ORN, open radical, nephrectomy; RRN, roboticradical nephrectomy.

Additional file 3. A total of 1111 patients undergoing partial and radical nephrectomy in development cohort.

Additional file 4. Characteristics of 751 patients after radical nephrectomy.

Additional file 5. Multivariable logistic regression analysis for predictors of postoperative AKI following radical nephrectomy.

\section{Abbreviations}

ACEls: Angiotensin-converting enzyme inhibitors/angiotensin receptor blockers; AKD: Acute kidney disease; AKI: Acute kidney injury; ALB: Albumin; ALP: Alkaline phosphatase; ALT: Alanine transaminase; ARBs: Angiotensin receptor blockers; AST: Aspartate transaminase; AUC: The area under the receiver operating characteristics curve; BMI: Body mass index; CCB: Calcium channel blocker; CHD: Coronary heart disease; $\mathrm{CHOL}$ : Cholesterol;

Cl: Confidence interval; CKD: Chronic kidney disease; CKD-EPI: The Chronic Kidney Disease Epidemiology Collaboration; DBP: Diastolic blood pressure; DM: Diabetes mellitus; eGFR: estimated glomerular filtration rate; FIB: Fibrinogen; FLD: Fatty liver disease; GLU: Glucose; Hb: Hemoglobin; HCT: Hematocrit; HDL: High density lipoprotein; ICU: Intensive care unit; KDIGO: Kidney Disease Improving Global Outcomes; LDH: Lactate dehydrogenase; MCH: Mean corpuscular hemoglobin; MCHC: Mean corpuscular hemoglobin concentration; MCV: Mean corpuscular volume; MPV: Mean platelet volume; NSAIDs: Non-steroidal anti-inflammatory drugs; OR: Odds ratio; PCT: Platelet crit; PLT: Platelet; PN: Partial nephrectomy; PPI: Proton pump inhibitor; PU: Peptic ulcer; RCC: Renal cell carcinoma; RN: Radical nephrectomy; SBP: Systolic blood pressure; Scr: Serum creatinine; SD: Standard deviation; STB: Total bilirubin; TG: Triglyceride; TP: Total protein; TT: Thrombin time; UA: Uric acid

\section{Acknowledgements \\ Not applicable.}

\section{Authors' contributions}

LY X and CY L was principal co-investigators, contributed to study design, implementation, data analysis, interpretation and draft the manuscript. LZ and BZ contributed to study design and data analysis, CJ L and XF M contributed to data acquisition, HL contributed to data analysis, LC and YF W contributed to revise the article. Y $X^{*}$ was the principal investigator, lead author, contributed to study design, implementation and interpretation, and was involved in the preparation of the manuscript. All authors read and approved the final manuscript.

\section{Funding}

This work was supported by the National Natural Science Foundation of China $(81170688,81470973$, and 81770679$)$. The funding body had no role in the design of the study and collection, analysis, and interpretation of data, or writing the manuscript.

\section{Availability of data and materials}

The datasets used and/or analysed during the current study available from the corresponding author on reasonable request.

\section{Ethics approval and consent to participate}

All subjects were treated with standard care without intervention from this study. All data were obtained via electronic medical records and a database review and were de-identified (the patient's name was replaced with an identification code, and the patient's private information was deleted before the analysis) to protect patient privacy. This study was approved by the ethics committee of the Affiliated Hospital of Qingdao University (QDFY WZ 2018-9-13) to screen out those patients with qualifying Scr levels.

\section{Consent for publication}

Not applicable.

\section{Competing interests}

The authors declare that they have no competing interests.

Received: 3 November 2018 Accepted: 4 May 2020

Published online: 14 May 2020

\section{References}

1. Rossi SH, Klatte T, Usher-Smith J, Stewart GD. Epidemiology and screening for renal cancer. World J Urol. 2018;36(9):1341-53.

2. Umer M, Mohib Y, Atif M, Nazim M. Skeletal metastasis in renal cell carcinoma: a review. Ann Med Surg (Lond). 2018;27:9-16.

3. Wang C, Li X, Peng L, Gou X, Fan J. An update on recent developments in rupture of renal angiomyolipoma. Medicine (Baltimore). 2018;97(16):e0497. 
4. Campbell SC, Novick AC, Belldegrun A, et al. Guideline for management of the clinical T1 renal mass. J Urol. 2009;182(4):1271-9.

5. Kutikov A, Smaldone MC, Egleston BL, Uzzo RG. Should partial nephrectomy be offered to all patients whenever technically feasible? Eur Urol. 2012;61(4): 732-4 discussion 734-5.

6. Van Poppel H, Da Pozzo L, Albrecht W, et al. A prospective randomized EORTC intergroup phase 3 study comparing the complications of elective nephron-sparing surgery and radical nephrectomy for low-stage renal cell carcinoma. Eur Urol. 2007;51(6):1606-15.

7. Robson CJ. Radical nephrectomy for renal cell carcinoma. J Urol. 1963;89: 37-42.

8. Ljungberg B, Alamdari Fl, Holmberg G, Granfors T, Duchek M. Radical nephrectomy is still preferable in the treatment of localized renal cell carcinoma. A long-term follow-up study. Eur Urol. 1998;33(1):79-85.

9. McKiernan J, Simmons R, Katz J, Russo P. Natural history of chronic renal insufficiency after partial and radical nephrectomy. Urology. 2002;59(6):816-20.

10. Thompson RH, Boorjian SA, Lohse CM, et al. Radical nephrectomy for pT1a renal masses may be associated with decreased overall survival compared with partial nephrectomy. J Urol. 2008;179(2):468-71 discussion 472-3.

11. Huang WC, Levey AS, Serio AM, et al. Chronic kidney disease after nephrectomy in patients with renal cortical tumours: a retrospective cohort study. Lancet Oncol. 2006;7(9):735-40.

12. Go AS, Chertow GM, Fan D, McCulloch CE, Hsu CY. Chronic kidney disease and the risks of death, cardiovascular events, and hospitalization. N Engl J Med. 2004;351(13):1296-305.

13. Tomaszewski JJ, Smaldone MC, Uzzo RG, Kutikov A. Is radical nephrectomy a legitimate therapeutic option in patients with renal masses amenable to nephron-sparing surgery? BJU Int. 2015;115(3):357-63.

14. Simhan J, Smaldone MC, Tsai KJ, et al. Objective measures of renal mass anatomic complexity predict rates of major complications following partial nephrectomy. Eur Urol. 2011;60(4):724-30.

15. Fergany AF, Hafez KS, Novick AC. Long-term results of nephron sparing surgery for localized renal cell carcinoma: 10-year followup. J Urol. 2000; 163(2):442-5.

16. Kopp RP, Mehrazin R, Palazzi KL, et al. Survival outcomes after radical and partial nephrectomy for clinical T2 renal tumours categorised by R.E.N.a.L. nephrometry score. BJU Int. 2014;114(5):708-18.

17. Corman JM, Penson DF, Hur K, et al. Comparison of complications after radical and partial nephrectomy: results from the National Veterans Administration Surgical Quality Improvement Program. BJU Int. 2000;86(7): 782-9.

18. Yokoyama M, Fujii $Y$, Takeshita $H$, et al. Renal function after radical nephrectomy: development and validation of predictive models in Japanese patients. Int J Urol. 2014;21(3):238-42.

19. Barlow $\sqcup$, Korets $R$, Laudano M, Benson M, McKiernan J. Predicting renal functional outcomes after surgery for renal cortical tumours: a multifactorial analysis. BJU Int. 2010;106(4):489-92.

20. Yokoyama $M$, Fujii $Y$, limura $Y$, et al. Longitudinal change in renal function after radical nephrectomy in Japanese patients with renal cortical tumors. J Urol. 2011;185(6):2066-71.

21. Schmid M, Abd-El-Barr AE, Gandaglia G, et al. Predictors of 30-day acute kidney injury following radical and partial nephrectomy for renal cell carcinoma. Urol Oncol. 2014:32(8):1259-66.

22. Yang L. Acute kidney injury in Asia. Kidney Dis (Basel). 2016;2(3):95-102.

23. Park JT. Postoperative acute kidney injury. Korean J Anesthesiol. 2017;70(3): 258-66.

24. Shin $\mathrm{S}$, Han $Y$, Park $H$, Chung YS, et al. Risk factors for acute kidney injury after radical nephrectomy and inferior vena cava thrombectomy for renal cell carcinoma. J Vasc Surg. 2013;58(4):1021-7.

25. Zabell JR, Wu J, Suk-Ouichai C, Campbell SC. Renal ischemia and functional outcomes following partial nephrectomy. Urol Clin North Am. 2017;44(2): 243-55.

26. Cadeddu JA, Ono Y, Clayman RV, et al. Laparoscopic nephrectomy for renal cell cancer: evaluation of efficacy and safety: a multicenter experience. Urology. 1998;52(5):773-7.

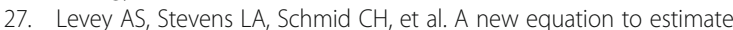
glomerular filtration rate. Ann Intern Med. 2009;150(9):604-12.

28. Oscanoa TJ, Amado JP, Romero-Ortuno R, Hidalgo JA. Estimation of the glomerular filtration rate in older individuals with serum creatinine-based equations: a systematic comparison between CKD-EPI and BIS1. Arch Gerontol Geriatr. 2018;75:139-45.
29. KDIGO AKI Work Group. KDIGO clinical practice guideline for acute kidney injury. Kidney Int Suppl. 2012;2:1-138.

30. Chawla LS, Bellomo R, Bihorac A, et al. Acute kidney disease and renal recovery: consensus report of the acute disease quality initiative (ADQI) 16 workgroup. Nat Rev Nephrol. 2017;13(4):241-57.

31. Stevens PE, Levin A, et al. Evaluation and management of chronic kidney disease: synopsis of the kidney disease: improving global outcomes 2012 clinical practice guideline. Ann Intern Med. 2013;158(11):825-30.

32. Golombos DM, Chughtai B, Trinh QD, et al. Minimally invasive vs open nephrectomy in the modern era: does approach matter? World J Urol. 2017; 35(10):1557-68.

33. Weight CJ, Lieser G, Larson BT, et al. Partial nephrectomy is associated with improved overall survival compared to radical nephrectomy in patients with unanticipated benign renal tumours. Eur Urol. 2010;58(2):293-8.

34. Grams ME, Sang Y, Ballew SH, et al. A meta-analysis of the Association of Estimated GFR, albuminuria, age, race, and sex with acute kidney injury. Am J Kidney Dis. 2015;66(4):591-601.

35. Utsumi T, Kamiya N, Kaga M, et al. Development of novel nomograms to predict renal functional outcomes after laparoscopic adrenalectomy in patients with primary aldosteronism. World J Urol. 2017;35(10):1577-83.

36. Wiedermann CJ, Wiedermann W, Joannidis M. Causal relationship between hypoalbuminemia and acute kidney injury. World J Nephrol. 2017;6(4):176-87.

37. Pickkers P, Heemskerk S, Schouten J, et al. Alkaline phosphatase for treatment of sepsis-induced acute kidney injury: a prospective randomized double-blind placebo-controlled trial. Crit Care. 2012;16(1):R14.

38. Wu C, Ke L, Tong $Z$, et al. Hypertriglyceridemia is a risk factor for acute kidney injury in the early phase of acute pancreatitis. Pancreas. 2014;43(8): 1312-6.

39. Hager MR, Narla AD, Tannock LR. Dyslipidemia in patients with chronic kidney disease. Rev Endocr Metab Disord. 2017;18(1):29-40.

40. Hur M, Koo CH, Lee HC, et al. Preoperative aspirin use and acute kidney injury after cardiac surgery: a propensity-score matched observational study. PLoS One. 2017;12(5):e0177201.

41. Sun J, Liu H. Perioperative treatment with aspirin or clonidine and risk of acute kidney injury. JAMA. 2015:313(11):1166.

42. Ilic LM, Davis RB, Brown RS, Lecker SH. The Interdialytic creatinine rise is a novel marker of volume overload and mortality risk in hemodialysis patients. BMC Nephrol. 2018;19(1):202.

43. Romagnani P, Remuzzi G, Glassock R, et al. Chronic kidney disease. Nat Rev Dis Primers. 2017;3:17088.

44. Levin A, Tonelli M, Bonventre J, et al. Global kidney health 2017 and beyond: a roadmap for closing gaps in care, research, and policy. Lancet. 2017;390(10105):1888-917.

\section{Publisher's Note}

Springer Nature remains neutral with regard to jurisdictional claims in published maps and institutional affiliations.

Ready to submit your research? Choose BMC and benefit from:

- fast, convenient online submission

- thorough peer review by experienced researchers in your field

- rapid publication on acceptance

- support for research data, including large and complex data types

- gold Open Access which fosters wider collaboration and increased citations

- maximum visibility for your research: over $100 \mathrm{M}$ website views per year

At $\mathrm{BMC}$, research is always in progress.

Learn more biomedcentral.com/submissions 